\title{
DIAGNÓSTICO DAS ÁREAS DE PRESERVAÇÃO PERMANENTE DE UM RIO TRANSFRONTEIRIÇO: O CASO DAS MARGENS DE UM SEGMENTO DO RIO QUARAÍ/CUAREÍM
}

\author{
Aline Andressa Bervig \\ Universidade Federal de Uberlândia - UFU \\ Instituto de Geografia, Uberlândia, MG, Brasil \\ alinebervig@gmail.com \\ Eliane Maria Foleto \\ Universidade Federal de Santa Maria - UFSM \\ Departamento de Geociências, Santa Maria, RS, Brasil \\ efoleto@gmail.com
}

\begin{abstract}
RESUMO
Tendo como ponto de referência o rio, as Áreas de Preservação Permanente (denominadas montes ribereños pela legislação uruguaia) são fundamentais para a preservação das suas margens e, consequentemente, do próprio recurso hídrico. A expansão do espaço urbano e/ou espaço agrícola acarreta a supressão das APP's, provocando dano ambiental. Nesse sentido, este trabalho teve como objetivo analisar as condições das APP's brasileiras e dos montes ribereños uruguaios, nas margens de um segmento do rio Quaraí/Cuareím, localizado na fronteira entre Brasil e Uruguai. Utilizando-se, inicialmente, da metodologia qualitativa de revisão bibliográfica, realizou-se uma comparação entre a legislação florestal e de recursos hídricos brasileira e a legislação ambiental uruguaia. Foram utilizadas imagens de satélite para localização e análise do trecho estudado na bacia hidrográfica do rio Quaraí, situado entre os afluentes arroio Pintado Grande, a Leste, e o arroio Tamandu a Oeste. Como resultado, verificou-se que existem APP's preservadas. Entre os usos irregulares das APP's podem se destacar a expansão do espaço urbano sob as margens do rio e o avanço das fronteiras agrícolas, acarretando a necessidade urgente de amenizar os problemas ambientais mencionados.
\end{abstract}

Palavras-chave: Área de preservação permanente. Rios transfronteiriços. Montes ribereños. Rio Quaraí.

\section{ANALYSIS OF THE AREAS OF PERMANENT PRESERVATION OF A CROSS-BORDER RIVER: THE CASE OF THE MARGINS OF A SEGMENT OF THE RIVER QUARAÍ/CUAREÍM}

\begin{abstract}
Taking the river as reference point, the permanent preservation areas (called montes ribereños by the urugayan law) are fundamental for the preservation of river banks and, consequently, of water resource itself. The expansion of urban space and/or agricultural space lead(s) to the suppression of PPAs, causing environmental damage. In this sense, this paper aimed at analyzing the conditions of brazilian PPAs and uruguayn montes ribereños on the banks of a segment of the Quaraí / Cuareím river, which is located in the border between Brazil and Uruguay. Taking, firstly, the qualitative methodology of bibliographical revision, it was made a comparison between the Brazilian forest law and water law and the Uruguayan environmental law. Satellite images were used to locate and analyze the space studied in the Quaraí river basin, between the Pintado Grande stream (east) and the Tamandu stream (west). Consequently, it was verified that there are preserved PPAs. The highlight the expansion of urban space under the banks of the river and the agricultural expansion are among the irregular uses of PPAs, leading to the urgent need of mitigating these environmental problems.
\end{abstract}

Keywords: Permanent preservation area. Cross-border flows. Coastal hills. Quarai River.

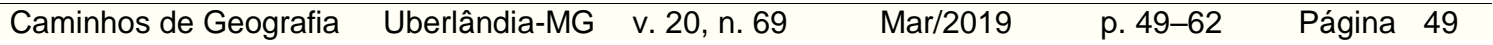




\section{INTRODUÇÃO}

Os rios têm importância e cultural na formação dos países, pois, serviram como vias de acesso a novas áreas e para a ocupação de novos territórios visando à exploração dos seus recursos naturais, além de tudo for plausível de interesse, principalmente, econômico. A exploração demasiada dos recursos naturais torna o ambiente insustentável e acarreta problemas ambientais. $\mathrm{Na}$ busca da mitigação dos impactos ambientais, a sociedade regula o uso e o manejo destes recursos por meio de leis e normas.

Quando esses recursos ocupam a área territorial de mais de um país, o que ocorre com os rios transfronteiriços, há a necessidade de acordos internacionais que busquem a padronização de normas e procedimentos, visando a preservação e a gestão compartilhada desses recursos. As áreas fronteiriças podem ser definidas conforme o pensamento a seguir:

As regiões transfronteiriças podem ser definidas como unidades territoriais delimitadas, com autoridades locais participando de processos de cooperação transfronteiriça. Essas regiões são o resultado de um processo de construção social, devendo ser entendidas como unidades sócioterritoriais equipadas com certo grau de capacidade estratégica na base de arranjos organizacionais. A fronteira entre Brasil e Uruguai se apresenta com uma institucionalização cada vez maior, intensificada pela entrada em vigor da Nova Agenda para Cooperação e Desenvolvimento Fronteiriço entre Brasil e Uruguai, em 2002. (PERKMANN, 2007, p. 157).

A proteção dos recursos hídricos não abrange apenas o curso d'água, mas toda a zona ripária, incluindo a vegetação ciliar e as Áreas de Preservação Permanentes (APP's), bem como rege o uso de toda a sua bacia hidrográfica. A preservação das áreas de influência do recurso hídrico tem importância na proteção do referido recurso, pois, a vegetação, por meio de suas raízes e estruturas, exerce papel de filtro e diminui o material contaminante que chega no curso d'água.

Para Zakia (1998) e Araújo (2002) a presença de mata ciliar nas zonas ripárias constitui condição básica para a manutenção da integridade dos processos hidrológicos e ecológicos devido a absorção do escoamento superficial pelo ecossistema ripário. O crescimento desordenado das cidades e das áreas de exploração agrícola são os principais motivos pelos quais ocorre a destruição das APP's, devido à ausência de planejamento de sua expansão, ocasionando prejuízos para a vegetação das margens dos rios.

Em áreas urbanas, as principais falhas na proteção das APP's se dão pela ineficiência do cumprimento das normas jurídicas que as protegem. Em áreas rurais, somado a este fator, a normatização frágil compatibiliza o uso da terra sem considerar a preservação desses recursos naturais (FINK e PEREIRA, 1996), dando origem aos problemas ambientais. Ressalta-se 0 pensamento a seguir:

À medida que a população aumenta, cresce a demanda por produtos agropecuários e consequentemente [sic], ocorre à expansão das áreas agrícolas, a intensidade de uso das terras e dos recursos naturais. A conversão de áreas de floresta em explorações agrícolas resulta em mudanças ambientais, especialmente na quantidade e qualidade da água, assoreamento dos rios e erosão. (SILVEIRA et.al., 2010, p. 173).

$\begin{array}{lllll}\text { Caminhos de Geografia } & \text { Uberlândia-MG } & \text { v. 20, n. } 69 & \text { Mar/2019 } & \text { p. 49-62 Página } 50\end{array}$


A existência das APP's nas margens dos rios contribui para a preservação dos mesmos, evitando a erosão, além de proporcionar a preservação da biodiversidade. Para Teixeira (2002) "O desafio da humanidade é conciliar o desenvolvimento com a proteção e a preservação ambiental, para não inviabilizar a qualidade de vida das futuras gerações, da coletividade e o exercício de propriedade sobre os bens ambientais."

Nesse sentido, o objetivo geral deste trabalho foi realizar um diagnóstico das Áreas de Preservação Permanente do rio transfronteiriço Quaraí. Ainda, como objetivos específicos, buscou-se analisar a legislação para definir a extensão das APP's/montes ribereños do Brasil e do Uruguai; elaborar os mapas de localização e do uso do solo através de imagens de satélite; verificar qual é a condição das APP's nos dois países e quantificar as áreas com incompatibilidade legal e as que estão conservadas.

O segmento do rio Quaraí analisado está situado entre o afluente arroio Pintado Grande a Leste e o arroio Tamandu a Oeste, e margeia as sedes dos Municípios de Quaraí/RS/Brasil e Artigas/Uruguai.

A escolha da área de estudo baseou-se na intensidade do uso do solo das margens do segmento do rio transfronteiriço Quaraí no trecho considerado, pois apresenta-se com supressão das APP's, provocado pelas expansões urbana e atividades agropecuárias. Verificou-se que a região próxima dos Municípios de Quaraí/RS/Brasil e do Departamento de Artigas/Uruguai demonstrou sofrer pressões nas suas APP's. Deste modo, visando a melhor interpretação das imagens de satélite CNES/Astrium, ao analisar as APP's optou-se por definir a área próxima dos Municípios de Quaraí/RS/Brasil e do Departamento de Artigas/Uruguai como foco desse trabalho.

\section{ÁREA DE ESTUDO}

O rio Quaraí é um afluente da margem esquerda do rio Uruguai, integrando a bacia do rio da Prata. A bacia do rio Quaraí possui uma área de drenagem de cerca de $14.800 \mathrm{~km}^{2}$, dos quais aproximadamente $6.700 \mathrm{~km}^{2}(45 \%)$ em território brasileiro e cerca de $8.100 \mathrm{~km}^{2}(55 \%)$ no extremo Noroeste do Uruguai. Esta é uma bacia transfronteiriça de águas compartilhadas entre o Brasil e o Uruguai, sendo a fronteira entre os países o curso principal do rio Quaraí conforme o Projeto Piloto de Gestão Integrada de Cheias na Bacia do Rio Quarai. (PPGICBRQ, 2005; VILLANUEVA et al.2002 e JUNGES, 2013).

O comprimento total da calha principal do rio Quaraí é de $351 \mathrm{~km}$, a diferença das cotas altimétricas, da nascente até o exutório, é de 326 metros, e a altitude média da bacia é de 200 metros. Situada entre os meridianos $55^{\circ} 35^{\prime} \mathrm{W}$ e $57^{\circ} 40^{\prime} \mathrm{W}$ e os paralelos $29^{\circ} 40^{\prime} \mathrm{S}$ e $30^{\circ} 55^{\prime} \mathrm{S}$, a bacia apresenta, segundo a classificação climática de Köppen, um clima temperado úmido, na variedade de clima subtropical do tipo "Cfa" (PPGICBRQ, 2005).

A nascente do rio Quaraí, no Brasil, é formada principalmente pelo arroio Quaraizinho. Já os seus afluentes são: arroio do Inglês, sanga Capão do Inglês, arroio Espinilho, arroio Passo da Lagoa, arroio Jeromito, sanga da Unha de Gato, sanga da Tuna, e os arroios dos Trilhos, Gaspar, Moirões, Invernada, Quaraí-Mirim, Salso, Areal, Cati, Pai-Passo, Garupá, Mancarrão e as sangas da Divisa e do Lajeado (BRASIL, 2013).

A nascente do rio Cuareím, no Uruguai, é formada pelo arroyo Catalán Grande e seus afluentes são: arroyo Pintado Grande, arroyo Tamandú, arroyo Yacaré e arroyo Cuaró y Yucutu (URUGUAY, 2000; 2013).

Nesse trabalho foram avaliadas as APP's de um segmento do rio Quaraí com aproximadamente 12 $\mathrm{km}$ de extensão que se encontra entre o arroyo Pintado Grande e o arroyo Tamandú, onde se

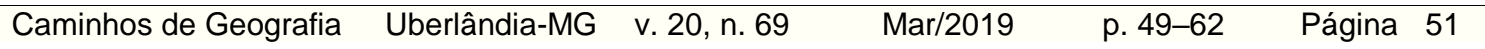


inserem as áreas urbanas dos Municípios de Quaraí/RS/Brasil e do Departamento de Artigas/Uruguai (Figura 1).

Figura 1 - Mapa de localização da área de estudo.

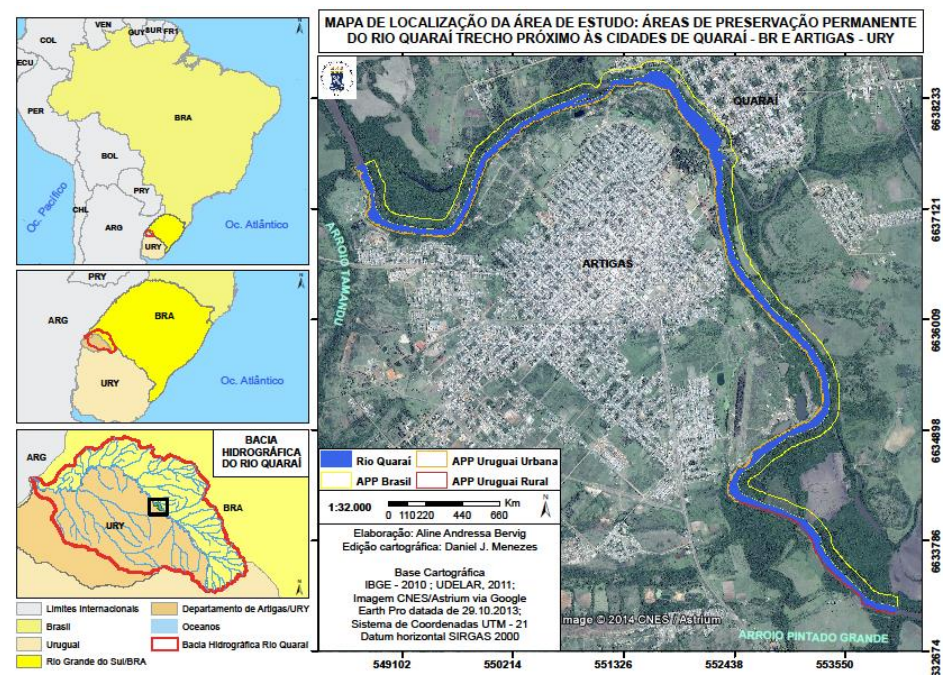

Elaboração - Bervig A.A. (2015). Edição cartográfica - Menezes D.J. (2015).

\section{METODOLOGIA}

A estrutura de ideias, teorias, conceitos, legislações, as comissões mistas e os acordos firmados na região nortearam a fundamentação teórica para a discussão dos resultados sobre as APP's.

$\mathrm{Na}$ segunda etapa do trabalho, realizou-se a coleta de dados das fontes cartográficas. As instituições públicas nacionais como Agência Nacional das Águas (ANA), Serviço Militar do Uruguai (SMU), Instituto Brasileiro de Geografia e Estatística (IBGE), Sistema de Referência e Geocêntrico das Américas SIRGAS e a Secretaria Estadual do Meio Ambiente e Desenvolvimento Sustentável (SEMA), a Prefeitura do Município de Quaraí/RS/Brasil e a Intendência Departamental de Artigas/Uruguai, formaram o campo de busca de informações, com imagens de satélite CNES/Astrium específicas da área analisada, que subsidiaram a compreensão da realidade das APP's.

$\mathrm{Na}$ terceira etapa foram obtidas imagens de satélite CNES/Astrium, através do software Google Earth Pro (2014), visando à delimitação da área objeto de estudo e delimitação de áreas de APP's.

Para a elaboração do mapa de localização, delimitação de áreas de APP's e também o de uso do solo, foi necessário, primeiramente, fazer um recorte espacial da área de estudo, visando a melhor qualidade da análise das APP's.

Dos 351 km de extensão do rio, o segmento considerado, situado entre os arroios Pintado Grande e arroio Tamandú, tem aproximadamente $12 \mathrm{~km}$ de comprimento, que passa pelas áreas urbanas dos municípios de Quaraí/RS/Brasil e de Artigas, do Departamento de Artigas/Uruguai.

Assim sendo, se buscou junto ao IBGE e a Universidade de Montevidéu (UDELAR) a melhor imagem de trabalho, sendo esta a imagem do satélite CNES/Astrium, via software Google Earth Pro, de 29/10/2013, com Sistema de Coordenadas UTM-21 e DATUM horizontal SIRGAS 2000. A escala utilizada para a representação cartográfica do segmento de rio foi de 1:20.000, porém, a escala visual das APP's foi de 1:3.000.

Para avaliar os usos e os conflitos atuais das APP's, foram geradas áreas de influência (buffers) a partir das margens do rio com larguras conforme as legislações vigentes no Brasil e no Uruguai. Inicialmente, com base na imagem do Google Earth Pro, foi gerado um polígono correspondente ao segmento de rio analisado (Figura 2A). O passo seguinte consistiu na representação (Figura 2B) da

$\begin{array}{lllll}\text { Caminhos de Geografia } & \text { Uberlândia-MG } & \text { v. 20, n. 69 Mar/2019 } & \text { p. 49-62 } & \text { Página } 52\end{array}$


APP's da margem brasileira que, com base no Código Florestal de 2012, Lei № 12.651, 25 de maio de 2012, deve ser de 100 metros considerando que a largura do rio no segmento analisado é de, aproximadamente, 30 metros.

O mesmo procedimento se deu para a margem uruguaia (Figura $2 \mathrm{C}$ ) onde as larguras das áreas de influência (buffers) se basearam na Ley Florestal de 1987, que exige 15 metros de vegetação quando o rio for em zona urbana, e 10 metros de vegetação quando o rio for em zona rural (Figura 2D).

Figura 2 - Buffers, com as imagens do software Google Earth Pro, para a elaboração do mapa do uso da terra nas margens do rio transfronteiriço Quaraí.

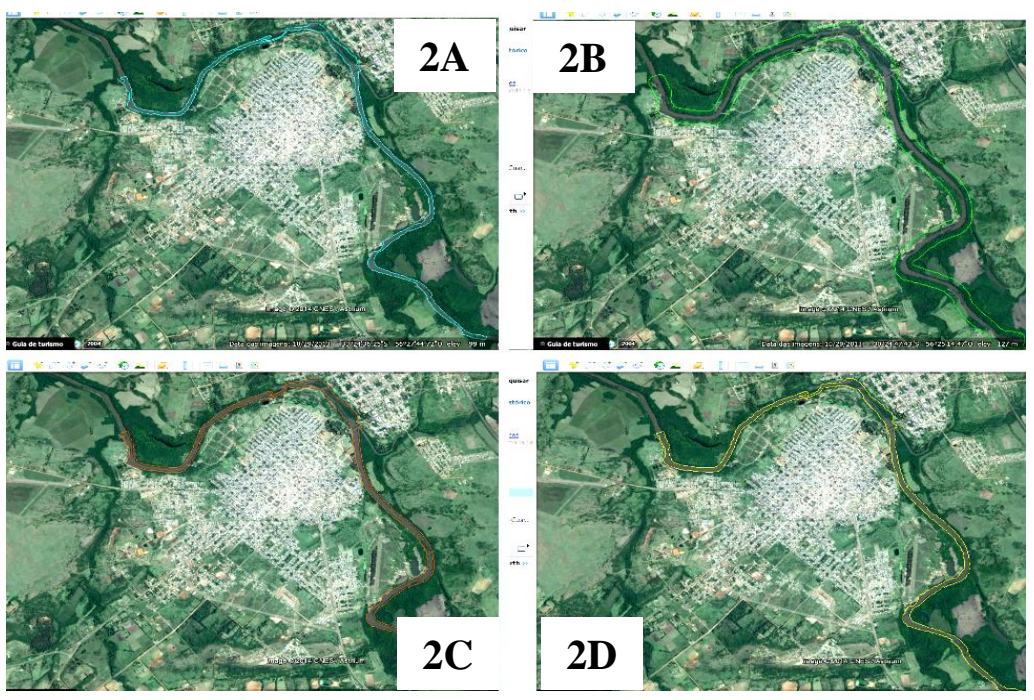

Elaboração - Bervig A.A. (2014).

Após essa etapa, foi feito o recorte manual dos polígonos referentes aos usos do solo nas áreas de APP's com as seguintes classes: a) área preservada onde o uso é campo e/ou presença de vegetação arbustiva e b) área de incompatibilidade legal que estão apresentadas no Quadro 1.

Quadro 1 - Formas do uso do solo no recorte espacial no segmento das margens do Rio Quaraí em Áreas de Preservação Permanente/montes ribereños.

\begin{tabular}{|c|c|}
\hline CLASSE & DINÂMICA SUPERFICIAL \\
\hline ÁREA PRESERVADA & APP's protegidas \\
\hline $\begin{array}{c}\text { ÁREA DE } \\
\text { INCOMPATIBILIDADE } \\
\text { LEGAL }\end{array}$ & $\begin{array}{r}\text { Uso urbano: Área ocupada por edificações, aberturas de vias e } \\
\text { impermeabilizações de ruas e demais estruturas das cidades. } \\
\text { Extração de areia: Locais onde ocorre extração de areia das margens } \\
\text { do rio e depósitos desses materiais nas margens. Locais sujeitos a } \\
\text { mudanças do curso do rio, de sua vazão e dinâmica do fluxo de água } \\
\text { e de material transportado. } \\
\text { Lavoura de arroz: Locais que foram desmatados, onde a vegetação foi } \\
\text { suprimida para dar lugar a lavouras de arroz. } \\
\text { Pecuária: Locais que forair desmatados para a ampliar as áreas de } \\
\text { campn, com o uso extensivo. }\end{array}$ \\
Solo Exposto: Áreas que estão sendo preparadas para a agricultura.
\end{tabular}

Elaboração - Bervig A.A. (2014).

$\begin{array}{lllll}\text { Caminhos de Geografia } & \text { Uberlândia-MG } & \text { v. 20, n. } 69 \quad \text { Mar/2019 } & \text { p. 49-62 Página } 53\end{array}$


A base cartográfica utilizada é da ESRI Word Base Map (2012). De acordo com a Resolução do IBGE P.PR - 1/2005 de 25/02/2005, foi utilizado o sistema de coordenadas UTM Fuso $22 \mathrm{~S}$ DATUM vertical SIRGAS 2000 para o banco de dados e apresentação final dos mapas.

\section{RESULTADOS E DISCUSSÃO}

O segmento do rio Quaraí, e a delimitação das APP's no Brasil e no Uruguai observa-se, inicialmente, que a largura das áreas de APP's no Brasil é maior do que no Uruguai. Nos $12 \mathrm{~km}$ de rio analisados, as áreas de APP's correspondem a 138 hectares, sendo que 18 hectares correspondem à margem uruguaia e 120 hectares a margem brasileira.

No Quadro 2 estão expostos a quantidade de hectares em cada classe e suas porcentagens. A legislação brasileira prevê 100 metros de APP's na margem de um rio com esta largura, já a legislação uruguaia, apenas, 15 metros em zona urbana e 10 metros na zona rural de montes ribereños, ou seja, uma faixa estreita de vegetação arbórea.

Quadro 2 - Porcentagens dos usos da terra no segmento do rio Quaraí nos Municípios de Quaraí/RS/Brasil e o Departamento de Artigas/Uruguai.

\begin{tabular}{|c|c|c|c|c|}
\hline \multirow{2}{*}{ CLASSE } & \multicolumn{2}{|c|}{ MARGEM BRASILEIRA } & \multicolumn{2}{c|}{ MARGEM URUGUAIA } \\
& \multicolumn{2}{|c|}{$\mathbf{1 2 0}$ ha } & \multicolumn{2}{c|}{} \\
\cline { 2 - 5 } & ha & $\%$ & ha & $\%$ \\
\hline ÁREA PRESERVADA & 85 & 70,8 & 15 & 83,5 \\
\hline $\begin{array}{c}\text { ÁREA DE INCOMPATIBILIDADE } \\
\text { LEGAL }\end{array}$ & 35 & 29,2 & 3 & 16,5 \\
\hline ÁREA TOTAL & $\mathbf{1 2 0}$ & $\mathbf{1 0 0}$ & $\mathbf{1 8}$ & $\mathbf{1 0 0}$ \\
\hline
\end{tabular}

Elaboração - Bervig A. A. (2015).

Conforme exposto no Quadro 2 a primeira informação que chama a atenção é que para o segmento de rio analisado, a área de APP's no Brasil é de 120 hectares e a da margem uruguaia é de 18 hectares, representando aproximadamente 15\% em área quando comparado ao Brasil. Isso significa que no Brasil a legislação é muito mais restritiva ao uso e limita mais a supressão das APP's se aproximando mais da proposta de Metzger (2010) da necessidade de ter 200 metros de vegetação arbórea. Isso se justifica, pois, o autor mencionado acima e (LAURANCE et al. 2002) mencionam que: "de uma forma geral, os efeitos mais intensos ocorrem nos 100 primeiros metros, o que implica que áreas com menos de $200 \mathrm{~m}$ são formados essencialmente por ambientes de borda, altamente perturbados."

Além desses autores, outros também sugerem que "corredores estreitos perderiam parte de sua utilidade, por favorecerem unicamente espécies generalistas, que suportam os efeitos de borda." (SANTOS et al. 2008; LOPES et al. 2009). E para (LAURANCE E LAURANCE 1999; LEES E PERES 2008) "espécies mais estritamente florestais necessitariam de corredores de pelo menos $200 \mathrm{~m}$ de largura” indo de encontro ao pensamento de Metzger (2010).

\section{Áreas Preservadas}

Nas APP's do Brasil, em um total de 120 ha, tem-se preservado com vegetação arbórea e campo nativo (Bioma Pampa) um total de 85 ha, conforme avaliado nessa pesquisa, isso representa

Caminhos de Geografia $\quad$ Uberlândia-MG $\quad$ v. 20, n. $69 \quad$ Mar/2019 $\quad$ p. 49-62 Página 54


aproximadamente $70,8 \%$ de área conservada. Em contrapartida, a área de montes ribereños no Uruguai num total de $18 \mathrm{ha}$, apresenta 15 ha de áreas conservadas, representando 83,3\%. Esses números indicam que, sob o ponto de vista legal, no Uruguai as APP's são mais preservadas do que no Brasil.

As áreas mais preservadas na margem brasileira, encontram-se a jusante da área urbana, ou seja, nos trechos de $n^{\circ} 1$ e 2 e a montante do rio das Tropas, nos trechos de $n^{\circ} 3,4$ e 5, conforme mapa da (Figura 3). Já na margem uruguaia, as áreas mais preservadas encontram-se a montante e junto ao núcleo urbano de Artigas.

Figura 3 - Localização dos trechos de $n^{\circ}$ 1, 2, 3, 4 e 5 no segmento do rio Quaraí.
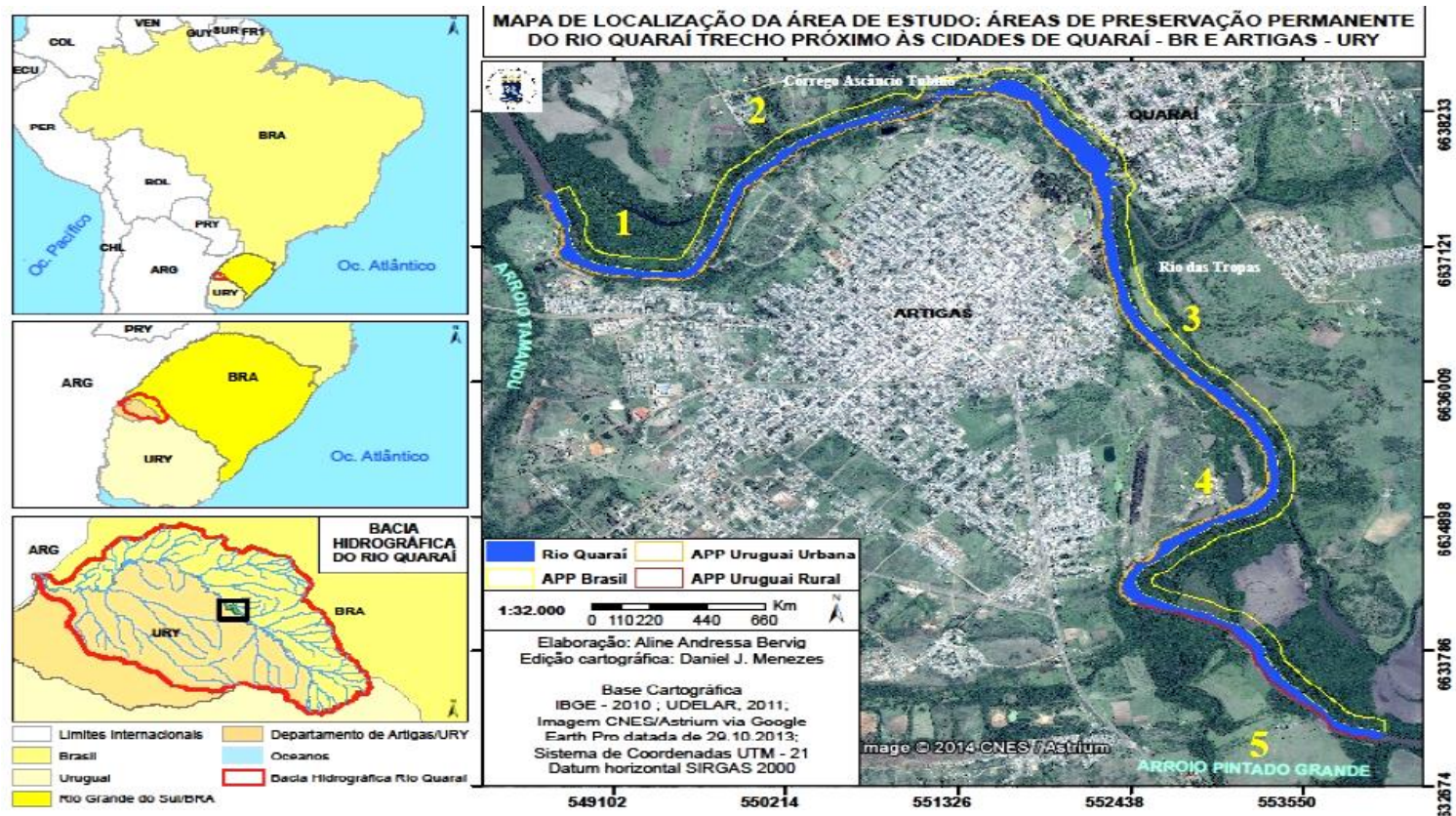

Elaboração - Aline Andressa Bervig (2015). Edição cartográfica - Daniel Junges Menezes (2015).

Considerando a largura das APP's da legislação brasileira, foi elaborada uma área de influência (buffer) de 100 metros para a margem uruguaia do rio Quaraí com o intuito de avaliar a preservação desta margem considerando a real funcionalidade e a manutenção dos ecossistemas a que essas áreas se propõe.

Analisando o segmento do rio na margem uruguaia com o buffer de 100 metros, a área preservada seria de $55 \%$, isto é, somente metade da área do que seria a APP's estaria, realmente, preservada. Em contrapartida as áreas que estariam em incompatibilidade ambiental seriam de $45 \%$, evidenciando, a necessidade de rever determinadas áreas que as APP's estão sendo suprimidas, seja para fins de expansão urbana ou agrícola.

Conforme exposto, estariam em desacordo $45 \%$ das áreas de montes ribereños na margem uruguaia com base no Código Florestal brasileiro, Lei $\mathrm{N}^{\circ} 12.651$, de 25 de maio de 2012, isso representa uma área de 49,16 ha. Já as que estariam de acordo seria 55\% das áreas de montes ribereños, representando uma área de 60,68\%.

A Figura n 4 mostra um trecho do segmento do rio Quaraí, onde se vê na margem uruguaia, (em vermelho), as áreas com supressão de APP's. Pode-se observar claramente que as áreas preservadas se encontram fragmentadas o que, segundo Metzger (2010), este fator dificulta a funcionalidade biológica dos corredores ecológicos. 
Figura 4 - Uso do solo nas áreas de preservação permanente no segmento do rio Quaraí nas cidades de Quaraí/ Brasil e Artigas/Uruguai.

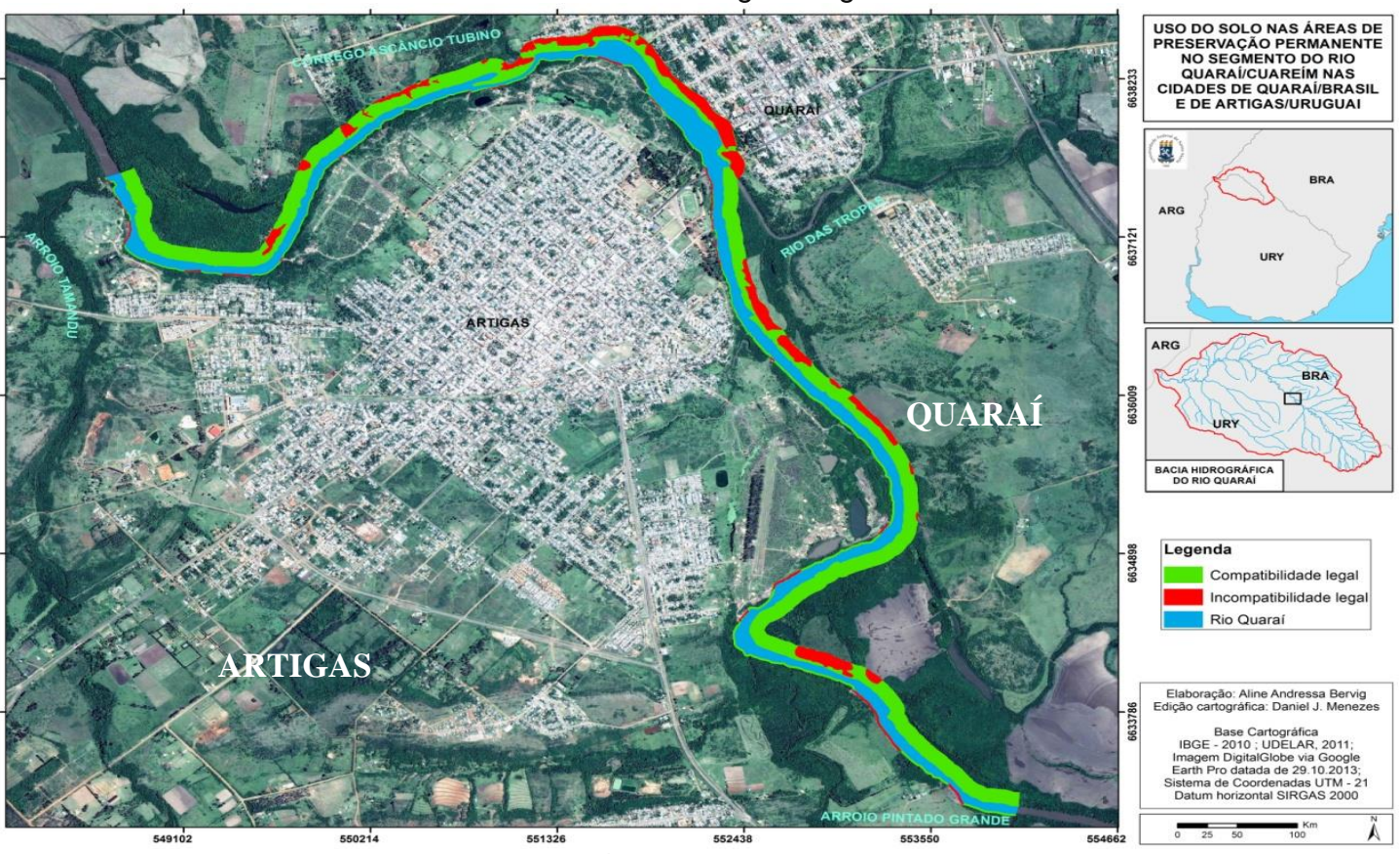

Elaboração - Bervig A. A. (2015)

\section{Áreas de Incompatibilidade Legal}

As áreas que deveriam ser preservadas e estão sendo utilizadas, por apresentaram uso irregular conforme as legislações vigentes no Brasil e no Uruguai são aquelas que apresentaram incompatibilidade legal. Dentre os usos do solo que suprimiram as áreas de preservação tomaram destaque o uso urbano ou uso agrícola.

A área urbana é considerada uma topologia de lugares e uma trama dos fluxos de circulações de um território [...] influenciado pelas relações internas e externas num processo dinâmico de adaptação e transformação do próprio espaço. (CORREA, 2006). Essa transformação se deu locais onde ocorreu a supressão das APP's no segmento do rio transfronteiriço Quaraí, conforme a (Figura 04). Nesse sentido e conforme a representação na figura, pode-se destacar que o uso do solo das APP's, no trecho do rio Quaraí na região próxima dos Municípios de Quaraí/RS/Brasil e da sede do Departamento de Artigas/Uruguai, do rio Quaraí, possui atividades variadas que não estão de acordo com as legislações vigentes no Brasil e no Uruguai.

A área de Município de Quaraí/RS/Brasil é menor se relacionada com o Departamento de Artigas/Uruguai. Mas, como a Legislação brasileira, Lei № 12.651, de 25 de maio de 2012, exige para a largura das APP's preservadas nas margens do rio Quaraí deve ser de $100 \mathrm{~m}$ acaba por adentrar as áreas que deveriam estar preservadas. E isso gera a supressão das APP's devido a expansão urbana.

Em contrapartida, a sede do Município de Artigas/Uruguai está mais afastada da margem e sob o efeito de uma legislação mais branda que exige a preservação de apenas 15 metros em área urbana. Dessa forma, a área urbana é maior, mas poucos locais estão inseridos em montes ribereños. Se a legislação fosse semelhante a existente no Brasil, o cenário seria diferente.

No segmento do rio Quaraí analisado percebeu-se supressão nas Áreas de Preservação Permanentes/montes ribereños com a presença de atividade urbana consolidada, sem observação das previsões legais.

Na Figura 5 a seguir foi exposto o avanço urbano de Quaraí/RS/Brasil sobre as APP's, colocando em risco essa região destinada a elas. 
Figura 5 - A) Imagem de satélite da região fronteiriça; B) Fotografia demonstrando o avanço da área urbana próxima as Áreas de Preservação Permanentes, no segmento do rio Quaraí, com destaque da cidade de Quaraí/RS/Brasil, no canto superior direito na foto.
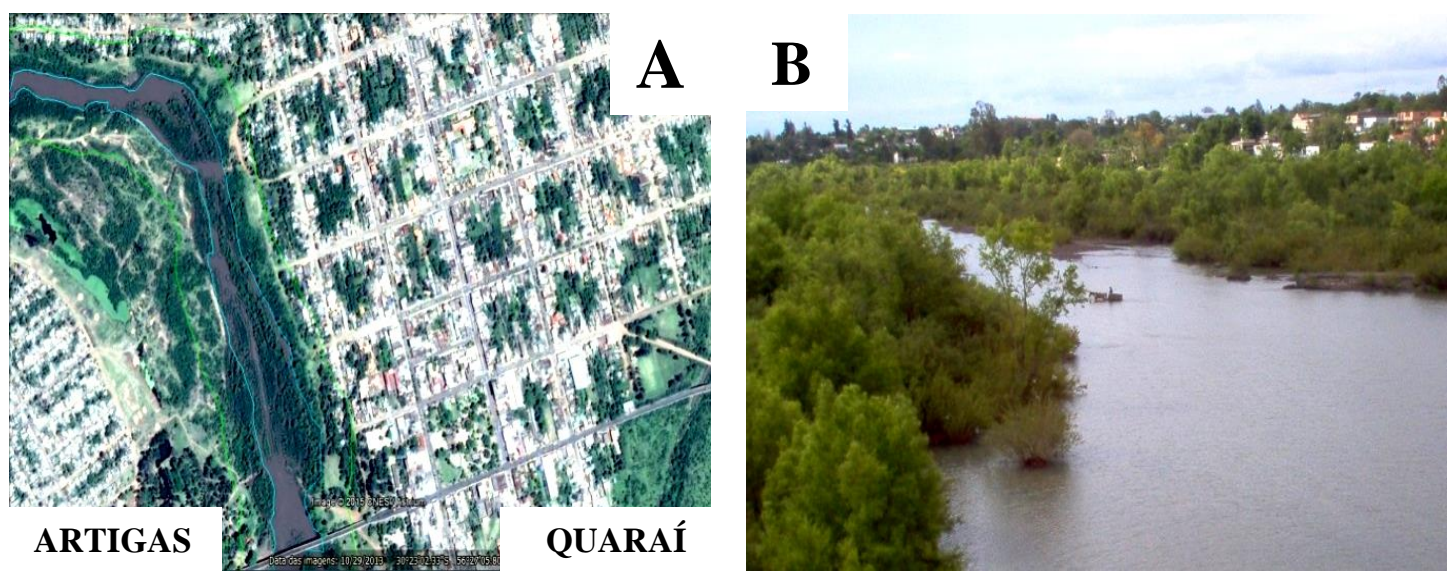

Autoria-BERVIG A. A. (2015).

Já na legislação uruguaia, que faz distinção em montes ribereños urbano e rural, a área urbana exige que se respeitem 15 metros, nem sempre observados nos casos de ocupação urbana irregular e de crescimento espontâneo e sem planejamento. Conforme exposto nas Figura 6 a seguir:

Figura 6 - Avanço da área urbana próxima as Áreas de Preservação Permanentes no segmento do Rio Quaraí, com destaque do Departamento de Artigas/Uruguai, no centro da foto.

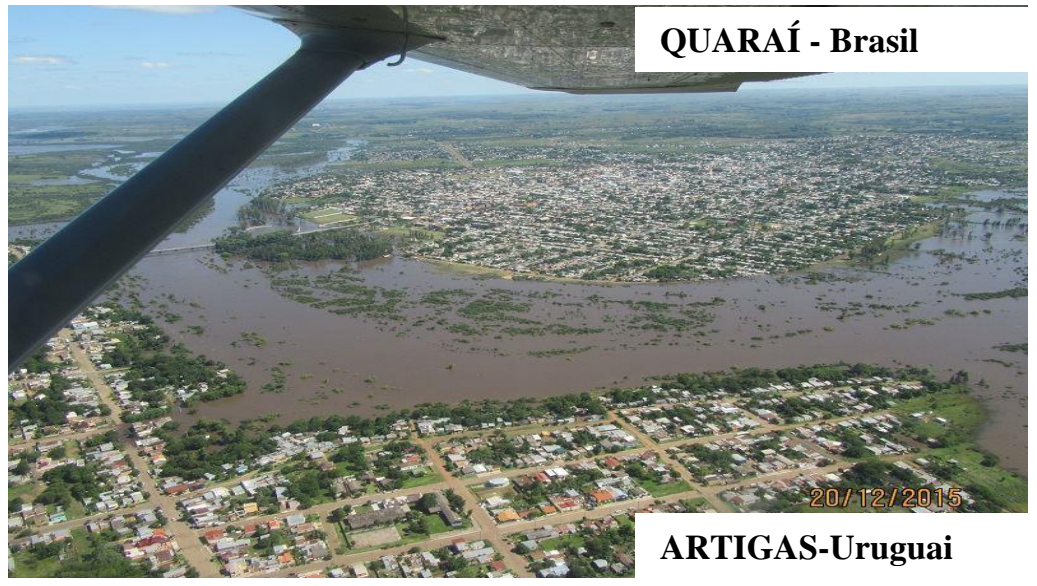

Foto - www.oquaraiense.com. Organização - BERVIG A. A. (2015).

É atribuição do Poder Público Municipal fiscalizar a supressão das APP's na área urbana, e devem possuir gestão compartilhada com auxílio das Comissões Mistas de Desenvolvimento presentes com enfoque no rio Quaraí, e estar disciplinados em Plano Diretor, instrumento que serve para a normatização urbana e políticas públicas, por meio do qual se determinam e se estabelecem as formas de uso do solo e de exercício do direito de propriedade.

Outro problema ambiental detectado nas margens do trecho do rio Quaraí é a existência de solo exposto, numa clara indicação de que algumas áreas serão utilizadas para fins agrícolas, fato recorrente na região. Na imagem de satélite do dia 29/10/2013 - (Figura 7) - é possível visualizar o solo exposto na margem brasileira e a uruguaia. O solo exposto na área de várzea é indicativo de preparo do solo para a rizicultura, em nas terras mais altas, para pastagens, representadas em ambas as margens. 
Figura 9 - A) Imagem de satélite referente ao segmento do rio Quaraí; B) Áreas de cultivo, respectivamente, de arroz, soja e eucalipto, nas proximidades do segmento das margens do rio Quaraí, margem brasileira, ao fundo.
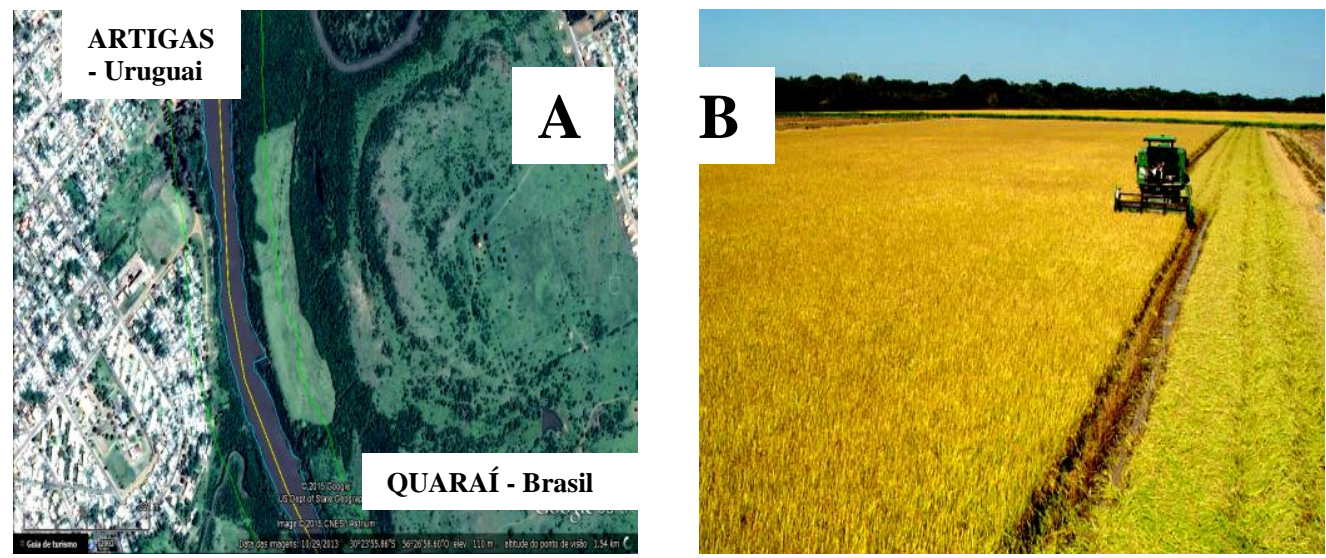

Fonte - EMATER (2014), Ministerio da Vivienda y Ordenamiento Territorial y Medio Ambiente del Uruguay MVOTMAU (2014) e Subrayado (2014). Elaboração - Bervig A. A. (2015).

Outra questão relevante é que, na região, existiu a preocupação com a pecuária extensiva, tanto para a bovinocultura quanto para a ovinocultura que existe a possibilidade dessas atividades serem exploradas em áreas mais afastadas da margem do rio Quaraí, podendo ser através da prática extensiva, porém isolando o acesso do gado às áreas que estejam em regeneração e próximas ao rio.

A atuação dos Órgãos ambientais competentes se torna primordial na implementação da gestão compartilhada e os Comitês Mistos de Desenvolvimento existentes na região auxiliariam nessa questão. Em alguns casos, a pecuária extensiva é realizada sem um sistema de pastoreio adequado, pois, os animais pastam livremente em uma grande área com pastagens razoáveis, sem a mínima condição de rebrota pelo grande volume de consumo pelos animais deixando, como consequência, o solo exposto.

A utilização do Sistema de Pastoreio Rotacional, mais conhecido como o manejo sustentável de Andre Voisin, (Figura 10) tem sido uma das principais técnicas adotadas no processo de intensificação dos sistemas pastoris. Além disso, os pastos são manejados alternadamente, ora com período de descanso, ora com período de ocupação, de tal forma que aumentam sua produtividade e diminuem a área a ser utilizada para inserir os animais. Essas medidas podem diminuir a necessidade de aumentar a área necessária para a pecuária, e, consequentemente, prevenir o avanço sobre as APP's.

Figura 10 - Demonstrativa do Manejo Sustentável de Andre Voisin.

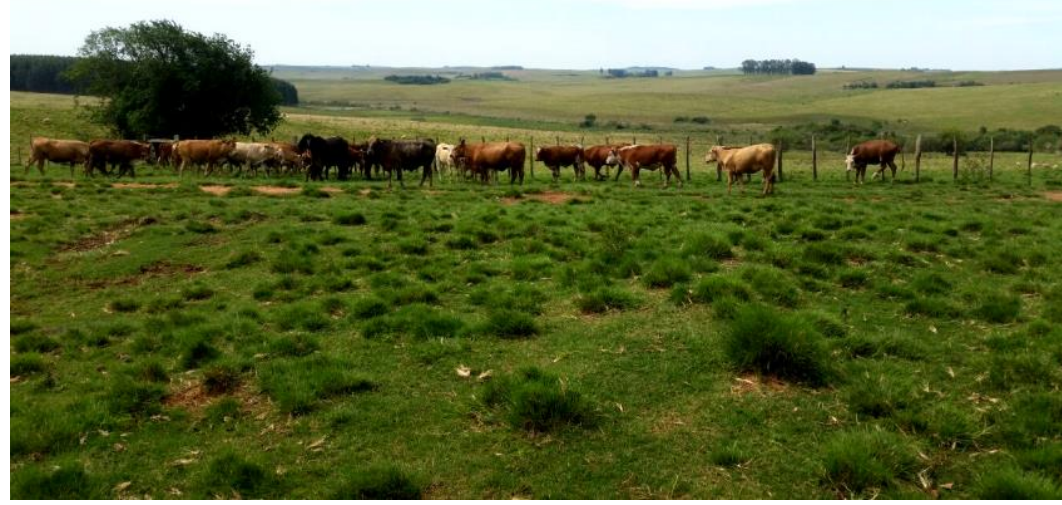

Fonte $-<$ http://www.campoegado.com.br/mobile/gado_detalhes?gadoid=3493\&pagenav=1>.

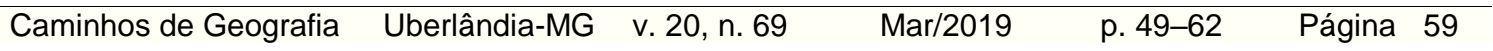


As informações e resultados deste estudo são essenciais para a visualização e compreensão das relações de uso dos recursos naturais nas áreas de fronteiras e para a identificação de ameaças a sua manutenção.

\section{CONSIDERAÇÕES FINAIS}

Conforme os resultados, a análise das APP's é importante para o conhecimento da realidade das condições das margens uruguaia e brasileira, do segmento do rio Quaraí analisado, com o foco nos Municípios de Quaraí/RS/Brasil e Artigas/Uruguai, confirmando-se a existência de degradação das Áreas de Preservação Permanentes (APP's)/montes ribereños nas margens do rio Quaraí, em ambos os países.

Entre os usos irregulares das APP's pode-se destacar a e o avanço das fronteiras agrícolas, acarretando a necessidade urgente de amenizar os problemas ambientais mencionados. A expansão urbana também se mostrou um problema na região. Há a necessidade de um maior monitoramento e efetiva fiscalização do cumprimento das legislações uruguaia e brasileira, assim, ocorrerá diminuição na degradação das margens deste rio e a necessária recuperação das áreas hoje degradadas. As Comissões Mistas de Desenvolvimento existentes devem buscar cada vez mais a gestão compartilhada na região, bem como na orientação da regulamentação das áreas citadas. A busca da melhoria da qualidade ambiental é uma necessidade de Estado, ou seja, é imprescindível que haja, cada vez mais, uma gestão compartilhada e eficaz na região do Rio Quaraí. Por isso a importância dos Comitês e das Comissões mencionadas ao longo do presente trabalho.

No aspecto da legislação existente, há a necessidade de que seja respeitada a base científica da existência do Código Florestal Brasileiro de 2012, Lei № 12.651, 25 de maio de 2012. Nesse sentido, existindo maior cumprimento das legislações vigentes no Brasil e no Uruguai, ocorrerá maior preservação ambiental. Para isso há necessidade de discussão acerca da base científica do Código Florestal, para a efetividade das faixas de vegetação remanescente certamente depende-se de uma série de fatores, dentre eles o tipo de serviço ecossistêmico considerado e a largura de vegetação preservada. No entanto, dada suas múltiplas características, incluindo: a topografia, a fixação do solo, a proteção dos recursos hídricos, o tipo de clima, a pluviosidade local a contenção de poluentes agrícolas, além da conservação da fauna, deve-se pensar na largura mínima suficiente para que esta faixa desempenhe de forma satisfatória todas as características. Por consequência, a definição desta largura no âmbito do Código Florestal deveria respeitar a função mais exigente. Em outras palavras, haveria a necessidade de homogeneizar a largura das APP's no segmento do rio Quaraí analisado. Se houver um aumento dessa área, principalmente, na margem uruguaia, a preservação será mais eficaz e a qualidade ambiental da região fronteiriça será melhorada. Com base no pensamento de (BARTON et. al. 1988; SANCHÉZ. et.al 2006) no entanto, se os montes ribereños são o habitat para muitos animais terrestres, além de importantes para todas as características acima mencionadas, então eles devem ser mais amplos. Para que tenham estabilidade, eles são de pouco valor se forem completamente eliminados ou demasiadamente diminuídos.

Para a maioria dos propósitos, seria preferível definir e padronizar a borda externa da área dos montes ribereños. Por exemplo, um buffer definido como $100 \mathrm{~m}$ de largura para cada margem do rio, proporcionaria um melhor conforto à população em geral, e buscaria aumentar as APP's. (BARTON et al., 1985)

Por fim, há a necessidade de conhecer as margens do rio Quaraí, mapeando as APP's em toda a sua extensão, e proporcionar esforços conjuntos buscando a possível recuperação das áreas de APP's degradadas. A temática é enriquecedora tanto para o conhecimento científico quanto para a população em geral, uma vez que há a necessidade de inter-relação dos diversos campos do conhecimento e aplicação nas atividades desenvolvidas na região.

\section{REFERÊNCIAS BIBLIOGRÁFICAS}

ARAÚJO, S.M.V.G. Áreas de Preservação Permanente e a questão urbana: estudo técnico consultoria legislativa da área de meio ambiente, direito ambiental, organização territorial, desenvolvimento urbano e regional. Brasília, DF: [s.n.], 2002.

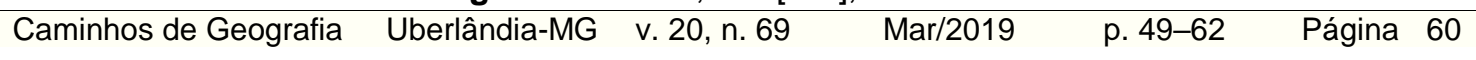


BARTON, D. R.; TAYLOR, W. D.; BIETTE, R. M. Dimensions of riparian buffer strips required to maintain trout habitat in southern Ontario streams. North Am. J. Fish. Manage. 5: 364-378. 1985. https://doi.org/10.1577/1548-8659(1985)5<364:DORBSR>2.0.CO;2

BRASIL, Água e Desenvolvimento Sustentável: Recursos Fronteiriços e Transfronteiriços do Brasil. Série Estudos Estratégicos. Secretaria de Estudos Estratégicos. Brasília/DF, Brasil. 2013.

CORRÊA, Roberto L. Estudos sobre a rede urbana. Rio de janeiro: Bertrand Brasil, 2006.

FINK, D. R. \& PEREIRA, M. S. Vegetação de Preservação Permanente e meio ambiente urbano. In: Revista de Direito Ambiental, ano 1, vol.2. São Paulo: Revista dos Tribunais, junho de 1996.

JUNGES, D. M. TRENTIN. R. A Demanda de Água Para Orizicultura e Gestão Transfronteiriça a Partir do Uso do Solo na bacia Hidrográfica do Rio Quaraí. Eixo: Bacias hidrográficas, processos fluviais e as repercussões sobre o espaço geográfico. XV Simpósio Brasileiro de Geografia Física Aplicada: Uso e Ocupação da Terra e as Mudanças das Paisagens. Vitória (ES), 8 a 12 de julho de 2013. Departamento de Geografia. CCHN. UFES.

LAURANCE S. G; LAURANCE W. F, Tropical wildlife corridors: Use of linear rainforest remnants by arboreal mammals. Biological Conservation, 91:231-239, 1999. https://doi.org/10.1016/S0006$\underline{3207(99) 00077-4}$

LAURANCE WF et al., Ecosystem decay of Amazonian forest fragments: a 22-year investigation. Conservation Biology, 16:605-618, 2002. https://doi.org/10.1016/S0006-3207(99)00077-4

LEES A. C; PERES C. A, Conservation value of remnant riparian forest corridors of varying quality for Amazonian birds and mammals. Conservation Biology, 22:439-449, 2008.

https://doi.org/10.1111/j.1523-1739.2007.00870.x

LOPES AV et al., Long-term erosion of tree reproductive trait diversity in edge-dominated Atlantic forest fragments. Biological Conservation, 142:1154-1165, 2009.

https://doi.org/10.1016/j.biocon.2009.01.007

METZGER, J.P. O Código Florestal tem base científica? J.P. Metzger, Conservação e Natureza, Universidade de São Paulo (USP), 2010. https://doi.org/10.4322/natcon.00801017

PERKMANN, M. Policy entrepreneurship and multilevel governance: a comparative study of European cross-border regions. Environment and Planning C: Government and Policy, v. 25, p. 861-879. 2007. https://doi.org/10.1068/c60m

PPGICBRQ, Projeto Piloto de Gestão Integrada de Cheias na Bacia do Rio Quarai. Informe Final. DNH (Dirección Nacional de Hidrografia del Uruguay) e IPH (Instituto de Pesquisas Hidráulicas, Brasil), 2005.

SANCHÉZ D. C.; GARCÍA M. A. C.; LÓPEZ-RÍOS G. F Ecología de las zonas ribereñas. Revista Chapingo Serie Ciencias Forestales y del Ambiente 12(1): 55-69, 2006.

SANTOS BA et al., Drastic erosion in functional attributes of tree assemblages in Atlantic forest fragments of northeastern Brazil. Biological Conservation, 141:249-260, 2008.

https://doi.org/10.1016/i.biocon.2007.09.018

SILVEIRA, F. et al. Análise Temporal do Uso e Ocupação do Solo e Qualidade da Água na Microbacia Ribeirão Irma, Massaranduba, SC. I Congresso Brasileiro de Organização do Espaço e X Seminário de Pós-Graduação em Geografia da UNESP - Rio Claro. 05 a 07 de outubro de 2010 - Rio Claro/SP.

TEIXEIRA, O. P. B. O Direito ao Meio Ambiente ecologicamente equilibrado como direito fundamental. Porto Alegre: Livraria do Advogado Ed., 2006.

URUGUAY, LEY DE ÁGUAS No. 276 del 27 de agosto de 1942. Disponível em: http:// www.hacienda.go.cr/.../Ley/Ley\%20276-\%20Ley\%...\%E2\%80\%8E (Acesso em: 2 de agosto de 2013). . Atlas Florestal, Direccíon Florestal (MGAP) - Ministério Ganadería, Agricultura y Pesca. Uruguay 2011. Disponível em: http://www.mgap.gub.uy/portal/hgxpp001.aspx?7,1...\% E2\%80\%8E (Acesso em: 26 de novembro de 2017).

Ley General de Protección del Medio Ambiente - La Protección del Medio

Ambiente, № 17.283 de 12 de Diciembre de 2000.

$\begin{array}{lllll}\text { Caminhos de Geografia } & \text { Uberlândia-MG } & \text { v. 20, n. } 69 & \text { Mar/2019 } & \text { p. 49-62 }\end{array}$ Página 61


Ministerio de Ganadería, Agricultura y Pesca, División Suelo y Agua, Zonificación de Tierras de la Cuenca Rio Cuareím - Evalución de dos Sistemas de Producción Bajo Riego Aportes a su Regulación Hídrica. MOLFINO, J. H.; MORELLI, C.; CALIFRA, A.; CLÉRICI, C.; PETRAGLIA, C. Proyecto FAO GCP / RLA / 126/ JPN. Deciembre 2000.

VILLANUEVA, A. O. N.; VIEGAS, J. S.; TRÖGER, F. H., Gestão Integrada de Inundações na Bacia Hidrográfica do Rio Quaraí / Cuareim (Brasil/Uruguai). Recompilação das Informações Básicas Existentes e Diagnóstico Preliminar (lado brasileiro). IPH/UFRGS, Global Water Partnership, Organização Meteorológica Mundial, 2002.

ZAKIA, M. J. B. Identificação e caracterização da zona ripária em uma microbacia experimental: implicações no manejo de bacias hidrográficas e na recomposição de florestas. 1998. 99 f. Tese (Doutorado em Ciências da Engenharia Ambiental) - Escola de Engenharia de São Carlos, SP, 1998. 